\title{
Analysis of Hazard Area of Dispersion Caused by Leakage from Underground Gas-Storage Caverns in Salt Rock
}

\author{
Ya Yang, Shigang Yang $\left(\mathbb{D}\right.$, Zhan Li ${ }^{\mathbb{D}}$, Qin Fang, Jianhua Wu, Jiongwei Cai, \\ and Wensheng Sun \\ National Defense College of Engineering, Army Engineering University of PLA, Nanjing 210007, China \\ Correspondence should be addressed to Shigang Yang; youngshg@126.com and Zhan Li; 1z.9008@163.com
}

Received 23 April 2020; Revised 19 October 2020; Accepted 30 October 2020; Published 18 December 2020

Academic Editor: Jian Ji

Copyright (c) 2020 Ya Yang et al. This is an open access article distributed under the Creative Commons Attribution License, which permits unrestricted use, distribution, and reproduction in any medium, provided the original work is properly cited.

\begin{abstract}
To provide information concerning quantitative risk analysis of gas-storage caverns, it is vital to estimate the hazard area of dispersion caused by accidental leakage. The Gaussian plume model is selected to calculate the hazard area caused by continuous leakage; the method of analysis is validated using wind-tunnel experiments of acetylene. Fluent is used to simulate the hazard area of dispersion caused by instantaneous leakage; the method of numerical simulation is verified by Burro/Coyote trials. Furthermore, a sample underground gas-storage cavern in salt rock is examined with respect to the toxic threshold limit value and the upper and lower flammability limits. In doing so, the factors that influence the hazard range of dispersion from salt cavern are discussed. The results indicate that the hazard area decreases with an increase in wind speed and a decrease in atmospheric stability when the leakage is continuous. However, the hazard area decreases with a decrease in wind speed when leakage is instantaneous.
\end{abstract}

\section{Introduction}

Deep underground salt caverns have been rapidly excavated and extensively utilized in developed European and American countries as "highly secure strategy energy reserve systems" ever since Canada first proposed the idea that rock caves can be used to store liquid and gas in the 1940s [1,2]. According to statistics, more than 600 seats of natural gas underground storage caverns can be found over the world, with $9.8 \%$ of reservoirs built-in salt rock formations. Indeed, underground storage is one of the safest ways of storing large quantities of hydrocarbons. However, gas can leak into the air through the injection-well casing due to the impact of the rheological and mechanical properties of salt rock and due to periodic pressure fluctuations, corrosion, and accidents in construction and general reservoir use [3-5].

The main component of natural gas stored in salt-rock caverns is methane, which is a pure asphyxiating gas, which is harmless under normal circumstances. However, the oxygen content in the air decreases when the concentration of methane is too high; moreover, when the methane content in the premixed gas cloud is $25 \%$ to $30 \%$, human beings can be affected by dizziness, headache, fatigue, increased breathing and heartbeat, ataxia, and suffocation. According to the occupational exposure concentration limits in Switzerland, the allowable toxic threshold limit value (TLV) of methane is $6,700 \mathrm{mg} / \mathrm{m}^{3}$ [6]. Repair personnel entering this concentration area need to wear protective equipment. If the concentration of a regional gas cloud is between the lower flammability limit (LFL) and the upper flammability limit (UFL), fire and/or explosions are highly possible, which can cause significant harm to humans and buildings. The flammability limit (volume fraction) of the natural gas is usually $5.3 \%$ to $15.1 \%$, corresponding to a concentration of $35,800-107,500 \mathrm{mg} / \mathrm{m}^{3}$ [7]. The area falling within the explosive concentration is called the explosive hazardous area; indeed, people located in this area should evacuate quickly. Therefore, the diffusion process of gas in the atmosphere requires examination after the injection-well casing of a salt-rock cavern fails, and the potential risk zones of gas leakage need to be determined. This will provide a scientific basis for the long-term use and safety control of underground storage caverns.

Many scholars have studied the risk of accidents from underground gas-storage caverns in salt rock. For example, 
the nonlinear creep behavior of salt rock was described with a LUBBY2 constitutive model and ADINA software, and the criteria-grading salt-rock reservoir stability was given through numerical analysis by Heusermann et al. [8]. The design parameters that influence surface uplift have been examined by Kim et al. [9]. Contrucci et al. established a high-resolution microseismic monitoring system by examining the cavern collapse and ground-subsidence phenomenon of the Cerville-Buissoncourt salt-rock reservoir in France [10]. The gaspermeation law of salt-rock gas-storage caverns containing sandwiches was studied by Chen et al. [11], and the groundsubsidence patterns of salt-rock gas-storage caverns after destruction was studied by Wang et al. [12]. The stability of salt-rock reservoirs was analyzed by $\mathrm{Ma}$ et al. [13], and the jetfire accident of salt-rock gas-storage caverns was evaluated by Yang et al. [14]. However, research concerning the security protection from leakage is currently lacking and hazard assessments on gas diffusion after leakage are yet to be reported. In this paper, the gas-diffusion model is analyzed and gasdiffusion hazards using relevant theoretical and numerical models, which are validated by experiments. Finally, a sample natural gas storage cavern in salt rock is analyzed with the proposed method and the dangerous areas associated with dispersion caused by leakage are determined according to industry occupational protection standards $[15,16]$.

\section{Analysis Model of Hazard Area Associated with Gas Dispersion}

The gas-diffusion mechanism has been a heavily debated topic ever since the 1980s. In particular, the flammable gasdiffusion mechanism has been studied using different methods by many scholars $[17,18]$. In doing so, selfpreparation programs and commercial software have been developed to simulate gas dispersion.

Experimental research is vital in studying (and developing) fluid mechanics. However, experimental methods require a lot of time and labor. Moreover, precision experimental results require fine modern testing equipment and techniques, and it is difficult to examine complex-flow problems [19]. Therefore, in this paper, the hazard area associated with dispersion caused by leakage from underground gas-storage caverns in salt rock is analyzed using theoretical analysis and numerical simulations.

2.1. Theoretical Analysis of Diffusion from Continuous Release. A number of gas-diffusion models are commonly used: Cox and Carpenter dense gas-diffusion model, the Britter and McQuaid model, the 3D finite-element model, the Gaussian model, the Sutton model, and the American Petroleum Institute gas-diffusion model. Among these models, the Gaussian model can be used with large amounts of data and sophisticated algorithms. In addition, it is relatively easy to use and its results are usually consistent with experimental results. Accordingly, it has been widely used [17, 20, 21].

For ground continuous-point source diffusion, the Gaussian plume model is commonly used to describe gas diffusion [7, 17, 22, 23].

(1) For $u>1 \mathrm{~m} / \mathrm{s}$, the concentration at the point $(x, y, z)$ where the origin is the leak source and the wind direction is the $x$-axis can be calculated as follows:

$$
C(x, y, z)=\frac{Q}{2 \pi u \sigma_{y} \sigma_{z}} \exp \left(-\frac{y^{2}}{2 \sigma_{y}^{2}}\right)\left\{\exp \left[-\frac{(z-H)^{2}}{2 \sigma_{z}^{2}}\right]+\exp \left[-\frac{(z+H)^{2}}{2 \sigma_{z}^{2}}\right]\right\}
$$

where $C(x, y, z)$ is the average concentration of the leakage gas at a certain point downwind $(x, y, z)$ $\left(\mathrm{kg} / \mathrm{m}^{3}\right) ; Q$ is the leakage source strength $(\mathrm{kg} / \mathrm{s}) ; u$ is the average wind speed $(\mathrm{m} / \mathrm{s}) ; H$ is the effective height of the leakage source, $(\mathrm{m}) ; \sigma_{x}, \sigma_{y}$ and $\sigma_{z}$ are the diffusion coefficient in the direction of $x, y$, and $z$-axis, respectively, $(\mathrm{m}) ; x$ is the downwind distance, $(\mathrm{m}) ; y$ is the crosswind distance, $(\mathrm{m}) ; z$ is the height above the ground, $(\mathrm{m})$.

(2) For $u<1 \mathrm{~m} / \mathrm{s}$, taking the continuous leakage as the overlay of instantaneous leakage $Q \Delta t$ in the time of $\Delta t$. Thus, the concentration at the point $(x, y, z)$ where the origin is the leak source and the wind direction is the $x$-axis can be calculated as follows:

$$
C(x, y, z, t)=\frac{Q_{m}}{(2 \pi)^{3 / 2} \sigma_{x} \sigma_{y} \sigma_{z}} \exp \left(-\frac{y^{2}}{2 \sigma_{y}^{2}}\right) \exp \left[-\frac{(x-u t)^{2}}{2 \sigma_{x}^{2}}\right]\left\{\exp \left[-\frac{(z-H)^{2}}{2 \sigma_{z}^{2}}\right]+\exp \left[-\frac{(z+H)^{2}}{2 \sigma_{z}^{2}}\right]\right\}
$$

where $C(x, y, z, t)$ is time average concentration, $\left(\mathrm{kg} / \mathrm{m}^{3}\right) ; t$ is release time $(\mathrm{s}) ; Q_{m}$ is total mass of material release $(\mathrm{kg})$.
2.2. Numerical-Analysis Method of the Diffusion from Instantaneous Release. Since the 1970s, the numerical method based on computational fluid dynamics (CFD) has been 
rapidly developing alongside the development of highpower computers and the development of computational methods, such as the finite-difference method, the finiteelement method, and the finite-volume method [24]. In addition, on the basis of the theoretical and experimental study, research institutions have developed a number of software systems based on CFD that can simulate gas diffusion, such as DEGADIS developed by the US Coast Guard and the Gas Institute Ltd., the HGSYSTEM developed by American Shell Institute Ltd with the support of 20 chemical and petrochemical companies, the EXSIM developed by the University of Aalbord in Denmark, FLACS developed by Christian Michelsen Institute in Norwegian, PHOENICS developed by the British CHAM Company, CFX developed by UK AEA Technology, STAR-CD developed jointly by Imperial College Institute and $\mathrm{CD}$-adapco Group, and Fluent developed by the FLUENT in the US [19, 25, 26].

\section{Model Validation}

3.1. Experimental Validation of Theoretical Analysis. A simple wind tunnel was designed and manufactured by $\mathrm{Xu}$ in 1998 [27], as shown in Figure 1. Using this wind tunnel, a number of tests of the horizontal injection diffusion were carried out at different discharge conditions; the actual concentration distribution of acetylene was obtained after gas diffusion and the general laws of gas diffusion were obtained by examining the wind speed and discharge rate. The test data are listed in Table 1.

The mass-volume concentration of acetylene in the wind-tunnel test was calculated using the Gaussian plume model (Equation (1), with the preferably atmospheric stability class $\mathrm{D}$ ), which was then converted into volumeconcentration using equation (3) and compared with experimental data. The results are shown in Figure 2.

$$
V=\frac{22.4 \cdot C}{M_{W}} \times 100,
$$

where $V$ is volume concentration (\%); $C$ is quality-volume concentration $\left(\mathrm{kg} / \mathrm{m}^{3}\right) ; M_{W}$ is molar mass $(\mathrm{kg} / \mathrm{kmol})$.

From Figure 2, it is evident that the theoretical volume concentration is essentially consistent with the results from the small wind-tunnel tests; with the increase of the gasrelease rate, the turbulence of the airflow in the position closer to the discharge pipe mouth is intensified, resulting in uneven mixing of acetylene and air, making the experimental result smaller. But any deviations between calculated and observed values are less than $20 \%$. Accordingly, using the Gaussian plume model is feasible and reasonable.

3.2. Experimental Validation of Numerical Analysis. The commercial software of Fluent was selected to simulate the gas-diffusion law. Burro/Coyote series trials were used as verification examples, which were completed by the Lawrence Livermore National Lab in China Lake of California in 1980. The trials concerned continuous leakage from liquefied natural gas (LNG) in the water surface, with a total of 18 diffusions and five combustion tests carried out. Two relatively integrated datasets were selected to validate the numerical simulations; the associated test conditions are shown in Table $2[28,29]$.

Numerical modeling (and unstructured grids) was carried out using Gambit software. The overall grid size is $5^{\circ} \mathrm{m}$; the mesh at the leak source was strengthened. Fluent software was used to simulate gas diffusion; the standard $k-\varepsilon$ turbulence model, incompressible ideal-gas model, and the pressure-based implicit solver were selected. The steadystate solver was utilized to construct a basic wind environment and to simulate gas leakage; the nonsteady-state solver was employed to simulate the diffusion process after the gas leakage stopped. Computational domain size and mesh division are shown in Figures 3 and 4; the calculation results are shown from Figures 5-8.

From Figures 5-8, the maximum distance of LNG horizontal and vertical diffusions calculated by Fluent software consistent with the measured values by test. Although the test results are asymmetric, this is because the wind direction and speed could not be kept constant during the tests; however, with numerical simulations, the wind field could be kept constant, resulting in a bias between the test results and simulation results. Therefore, it is feasible to use fluent software to calculate the instantaneous diffusion concentration distribution of gas.

\section{Sample Computation and Parametric Study}

An injection station of the underground gas-storage cavern in salt rock is examined in this section. The accident scene was set for injection-casing leakage due to corrosion (or other reasons) and the impact of the leakage on the surrounding area was studied, as shown in Figure 9. Leakage source was located at the center of the ground, with the coordinates $(67,62,0)$; the diameter of the injection casing was $216 \mathrm{~mm}$, gas injection direction was vertical to the ground, and the leak-source strength of natural gas (or methane) was $173 \mathrm{~kg} / \mathrm{s}$, all of which were set according to the existing literature [30]. When chain self-preservation of the instrument is not normal, it needs to manually switch the valve, including the time taken in wearing air respirators, journey, and switching valves. The time of controlling leakage needs 5 min $[20,31]$. Accordingly, the time of continuous leakage is five minutes, after which the point of free diffusion following the wind field occurs. Wind speed is, respectively, 2,5 , and $10 \mathrm{~m} / \mathrm{s}$ from west to east. The law of the concentration distribution of methane leakage and diffusion (and its impact on the surrounding residents) for different wind speeds was analyzed using theoretical analysis and numerical simulations.

4.1. Theoretical-Calculation Results and Discussion. For gastransportation pipelines, the leak-diffusion model can describe the ground continuous-point source diffusion when pipeline rupture or perforation occurs. Hazardous areas of natural gas continuous leakage and the diffusion from gasstorage caverns in salt rock calculated by the Gaussian plume model are shown in Figures 10 and 11, respectively. 


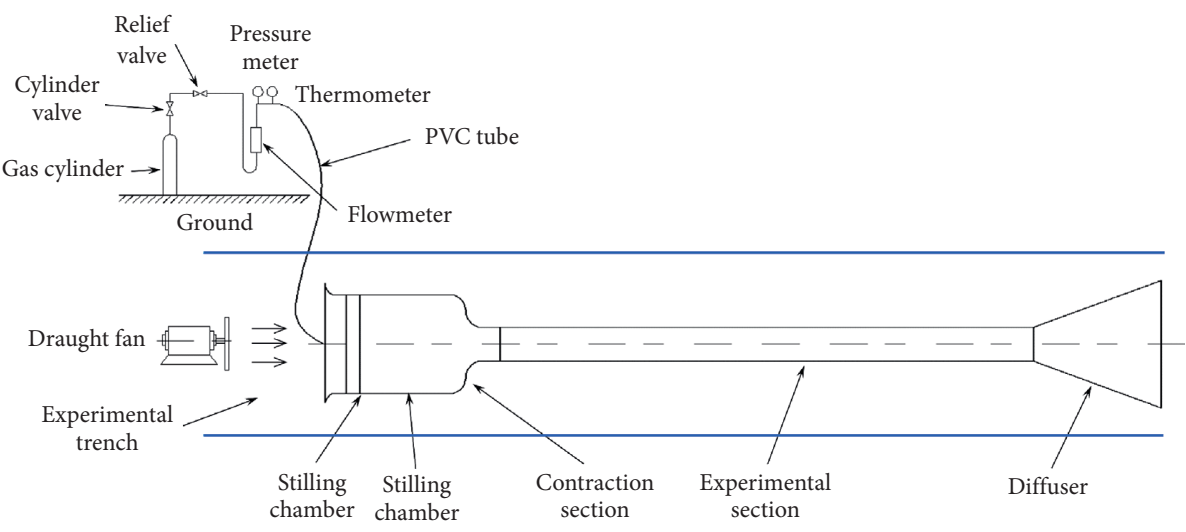

FIgURE 1: Schematic diagram of the experimental system [27].

Table 1: Wind-tunnel test data of acetylene diffusion [27].

\begin{tabular}{|c|c|c|c|c|c|c|}
\hline \multirow{3}{*}{\multicolumn{2}{|c|}{ Height $(\mathrm{m})$}} & \multicolumn{5}{|c|}{ Concentration (V/\%) } \\
\hline & & \multicolumn{4}{|c|}{ Downwind distance $(\mathrm{m})$} & \multirow{2}{*}{ Test conditions } \\
\hline & & 1 & 2 & 3 & 4 & \\
\hline \multirow{7}{*}{ Test 1} & 0.81 & & 0.0 & 0.0 & 0.0 & \\
\hline & 0.69 & & 0.054 & 0.201 & 0.0165 & Discharge rate $6 \mathrm{~m}^{3} / \mathrm{h}$ \\
\hline & 0.57 & 1.004 & 0.729 & 0.463 & 0.189 & The average wind speed $2.0 \mathrm{~m} / \mathrm{s}$ \\
\hline & 0.45 & 5.77 & 1.666 & 0.732 & 0.461 & Gas temperature $-10^{\circ} \mathrm{C}$ \\
\hline & 0.33 & 1.262 & 0.776 & 0.469 & 0.287 & Discharge time $3 \mathrm{~min}$ \\
\hline & 0.21 & & 0.358 & 0.221 & 0.0253 & Ambient temperature $-10^{\circ} \mathrm{C}$ \\
\hline & 0.09 & & 0.0 & 0.053 & 0.0 & \\
\hline \multirow{7}{*}{ Test 2} & 0.81 & & 0.0 & 0.053 & 0.028 & \\
\hline & 0.69 & 0.0 & 0.0 & 0.13 & 0.302 & Discharge rate $8 \mathrm{~m}^{3} / \mathrm{h}$ \\
\hline & 0.57 & 1.298 & 0.775 & 0.532 & 0.38 & The average wind speed $2.0 \mathrm{~m} / \mathrm{s}$ \\
\hline & 0.45 & 6.245 & 1.865 & 0.758 & 0.53 & Gas temperature $-10^{\circ} \mathrm{C}$ \\
\hline & 0.33 & 1.31 & 0.823 & 0.483 & 0.23 & Discharge time $3 \mathrm{~min}$ \\
\hline & 0.21 & & 0.0 & 0.22 & 0.103 & Ambient temperature $-10^{\circ} \mathrm{C}$ \\
\hline & 0.09 & & 0.0 & 0.0 & 0.082 & \\
\hline
\end{tabular}

Note. The value in the location of the underline is the maximum concentration.

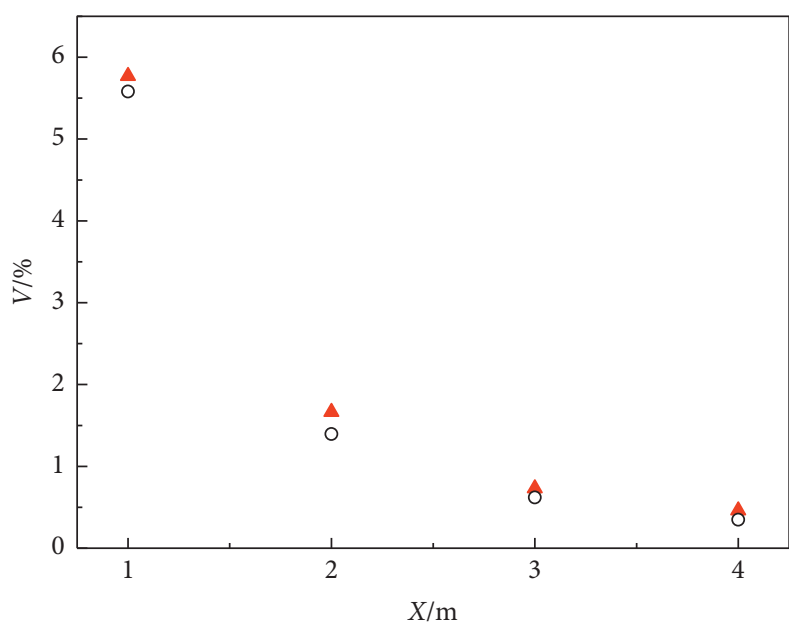

- Wind tunnel test

- Gaussian plume model

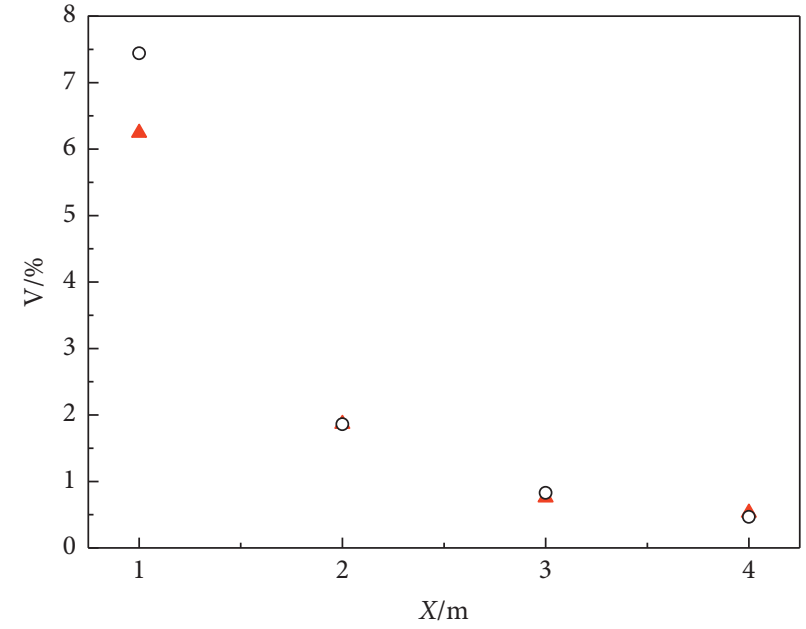

- Wind tunnel test

- Gaussian plume model

(a)

(b)

Figure 2: Volume-concentration distribution of different downwind distances from a height of $0.45 \mathrm{~m}$ (a) Test 1 . (b) Test 2. 
TABLE 2: Weather and release conditions in Burro/Coyote series trials [28, 29].

\begin{tabular}{lcccccccc}
\hline $\begin{array}{l}\text { Trial } \\
\text { number }\end{array}$ & $\begin{array}{c}\text { Liquid pool } \\
\text { diameter }(\mathrm{m})\end{array}$ & $\begin{array}{c}\text { Release rate } \\
\left(\mathrm{m}^{3} / \mathrm{min}\right)\end{array}$ & $\begin{array}{c}\text { Gas } \\
\text { temperature } \\
\left({ }^{\circ} \mathrm{C}\right)\end{array}$ & $\begin{array}{c}\text { Release } \\
\text { time }(\mathrm{s})\end{array}$ & $\begin{array}{c}\text { Wind } \\
\text { speed } \\
(\mathrm{m} / \mathrm{s})\end{array}$ & $\begin{array}{c}\text { Relative } \\
\text { humidity }(\%)\end{array}$ & $\begin{array}{c}\text { Atmospheric } \\
\text { stability class }\end{array}$ & $\begin{array}{c}\text { Ambient } \\
\text { temperature }\left({ }^{\circ} \mathrm{C}\right)\end{array}$ \\
\hline B9 & 58 & 18.4 & -164 & 79 & 5.7 & 13.1 & $\mathrm{D}$ & 35.4 \\
$\mathrm{C} 3$ & 58 & 13.5 & -164 & 65 & 6.0 & 11.3 & $\mathrm{~A}$ & 38.3 \\
\hline
\end{tabular}

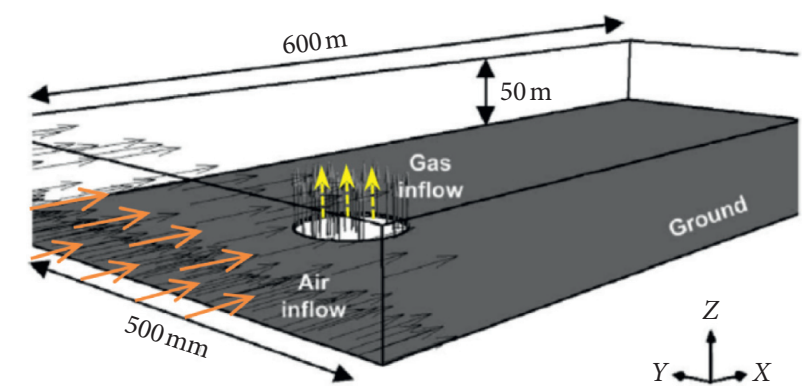

Figure 3: Computational domain size and boundary conditions [28, 29].

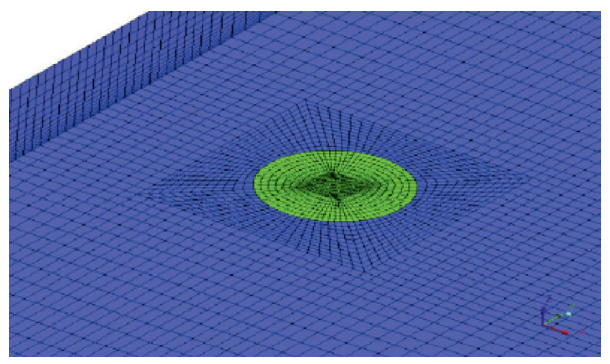

Figure 4: Partial mesh.
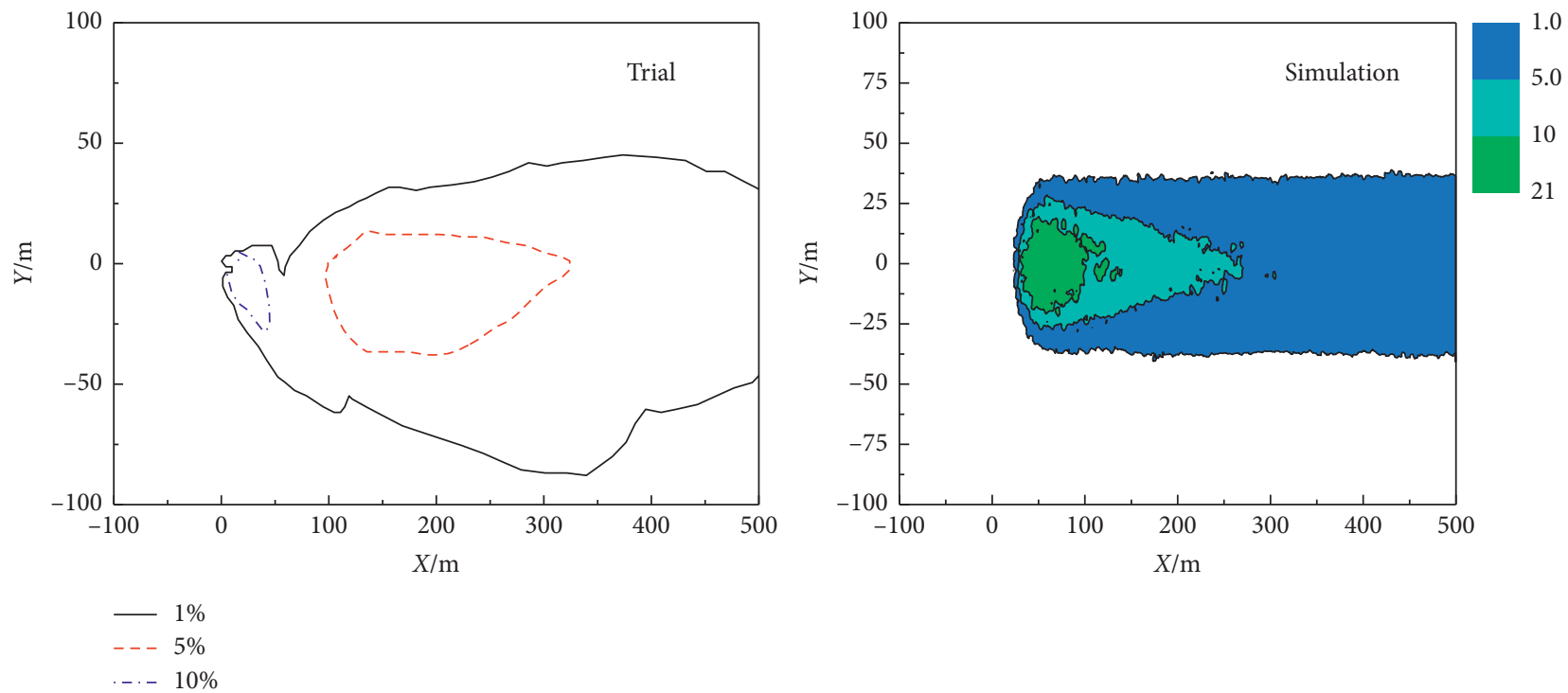

FIgURE 5: Comparison of Burro 9 trial and Fluent simulation for LNG horizontal volume-concentration distribution $(Z=1 \mathrm{~m}$ and $t=80 \mathrm{~s})$.

According to Figure 10, fast wind speeds are conducive to gas diffusion; moreover, the hazard area is small when continuous leakage occurs for fast wind speeds. Gas diffusion is the slowest under calm wind conditions and harm is relatively serious. For example, if the injection-well casing is completely broken, and if the wind speed is $2 \mathrm{~m} / \mathrm{s}$, the maximum diffusion 

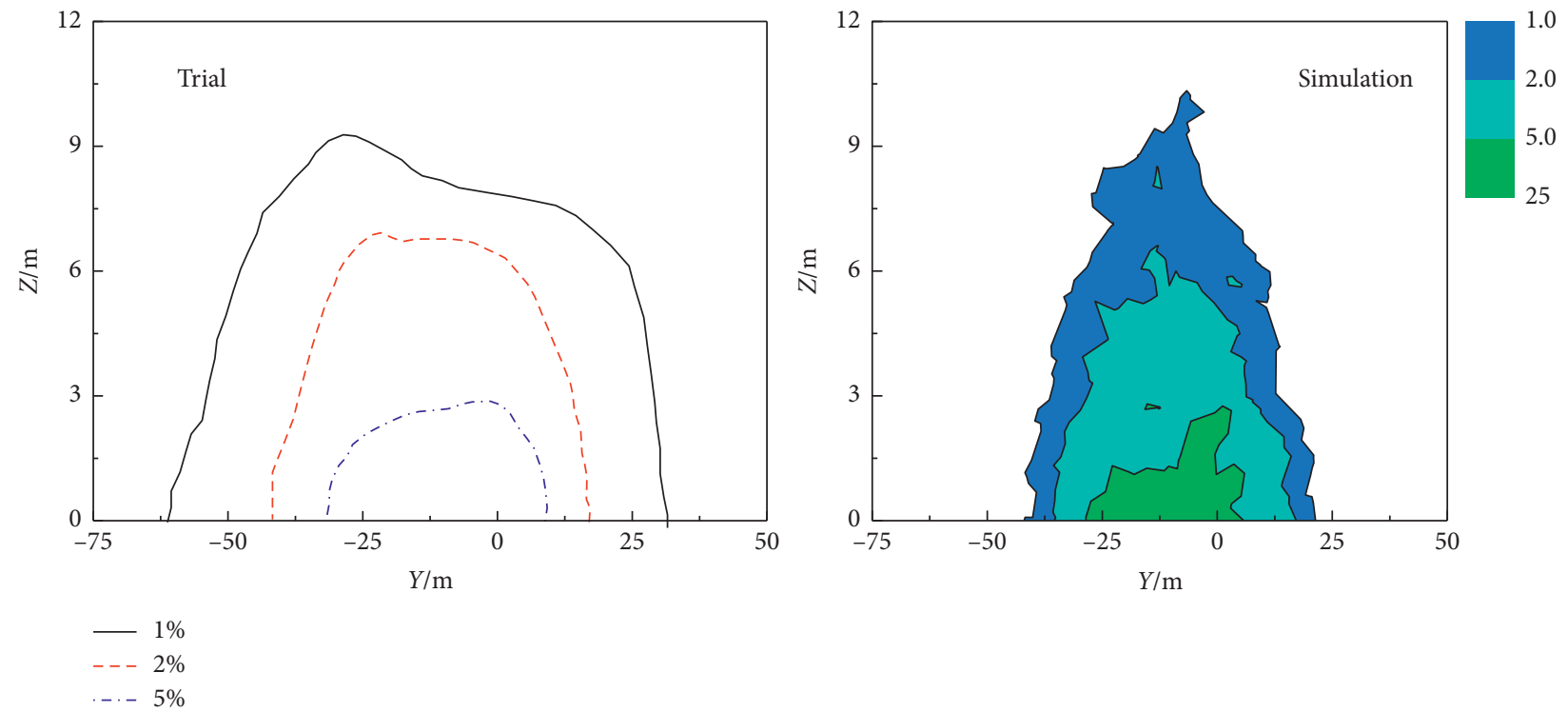

Figure 6: Comparison of Burro 9 trial and Fluent simulation for LNG vertical volume-concentration distribution $(X=140 \mathrm{~m}$ and $t=80 \mathrm{~s})$.
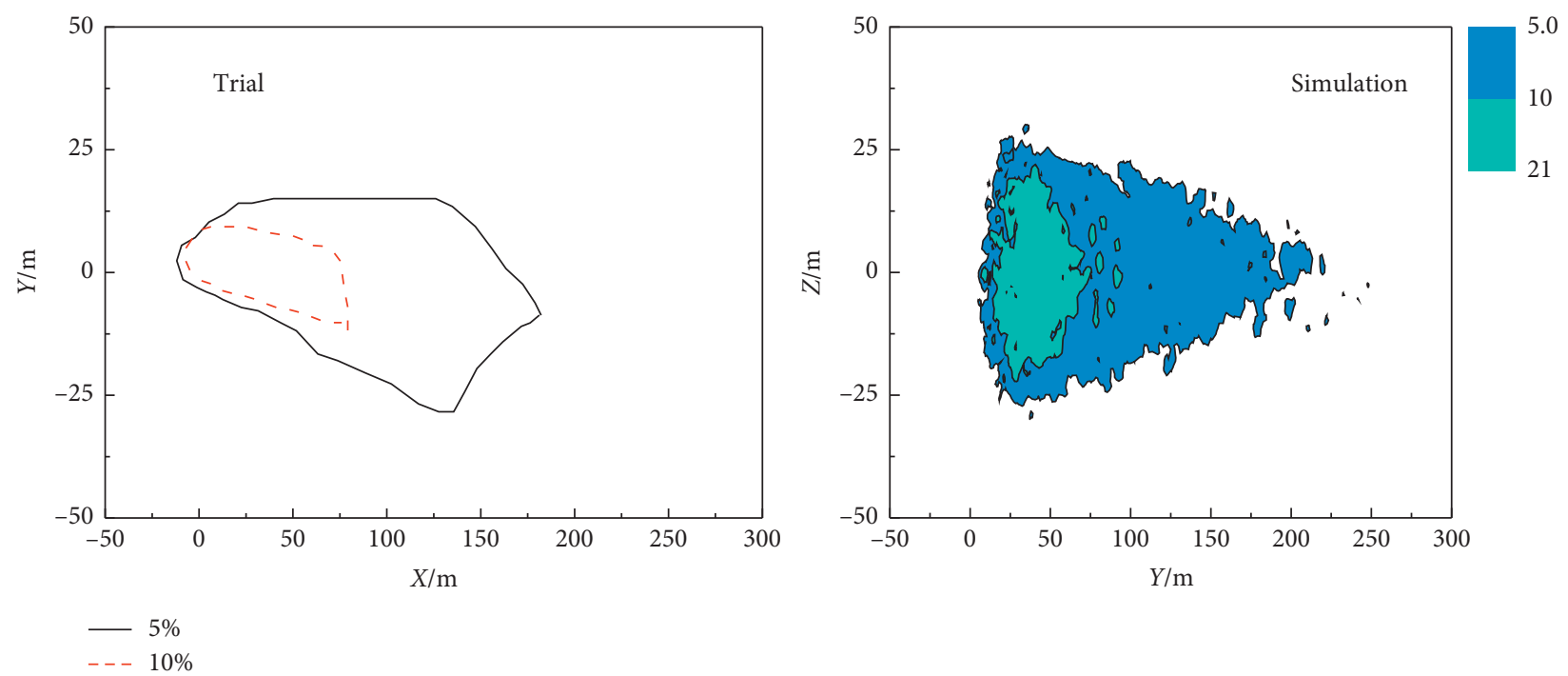

Figure 7: Comparison of Coyote 3 trial and Fluent simulation for LNG horizontal volume-concentration distribution $(Z=1 \mathrm{~m}$ and $t=100 \mathrm{~s})$.

distance for the downwind direction corresponding to the concentrations of TLV, LFL, and UFL is 315,135 , and $80 \mathrm{~m}$, respectively; if the wind speed is $10 \mathrm{~m} / \mathrm{s}$, the distances are 140 , 60 , and $35 \mathrm{~m}$, respectively. In addition, the maximum diffusion distance at the crosswind direction is small when the wind speed is fast. For instance, if the wind speed is $2 \mathrm{~m} / \mathrm{s}$, the maximum diffusion distance at the crosswind direction corresponding to the concentrations of TLV, LFL, and UFL is 60, 25 , and $12 \mathrm{~m}$, respectively; if the wind speed is $10 \mathrm{~m} / \mathrm{s}$, the distances are 25,10 , and $5 \mathrm{~m}$, respectively.

According to Figure 11, an unstable atmosphere is conducive to gas diffusion and the hazard area is small when continuous gas leakage occurs. For instance, if the atmospheric stability class is $\mathrm{B}$, the maximum diffusion distance for the downwind direction corresponding to the concentrations of TLV, LFL, and UFL is 240,105, and $60 \mathrm{~m}$, respectively; if the atmospheric stability class is $D$, the distances are 460, 190, and $110 \mathrm{~m}$, respectively. Indeed, the atmospheric stability class has almost no effect on the maximum diffusion distance in the crosswind direction.

4.2. Numerical-Simulation Results and Discussion. The emergency shut-off valve is usually set in the injection-well casings of underground gas-storage caverns. The valve at both ends is automatically sealed off when pipeline rupture 

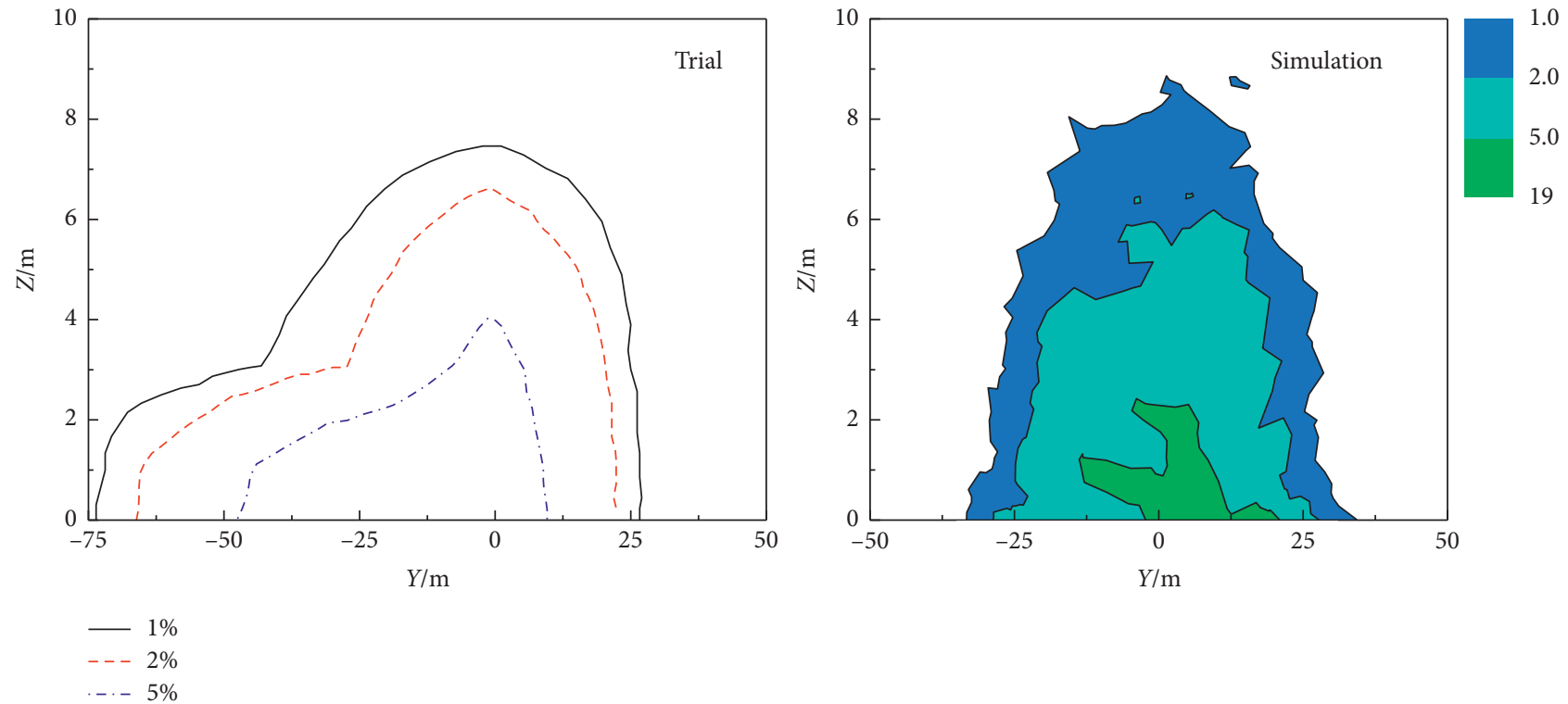

FIGURE 8: Comparison of Coyote 3 trial and Fluent simulation for LNG vertical volume-concentration distribution $(X=140 \mathrm{~m}$ and $t=100 \mathrm{~s})$.

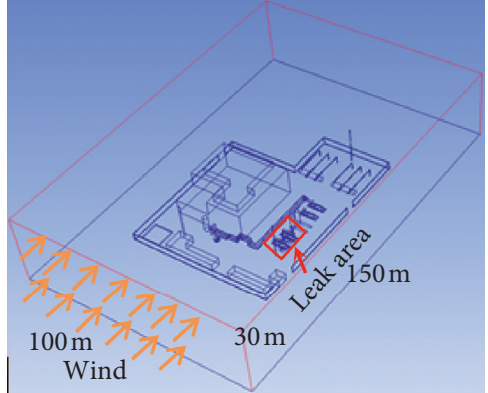

(a)

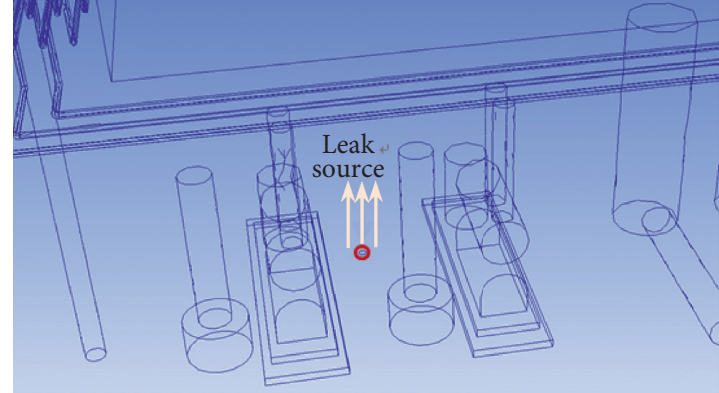

(b)

Figure 9: Schematic diagram of leakage scene. (a) The geometry of the injection station. (b) Location of the leak source.

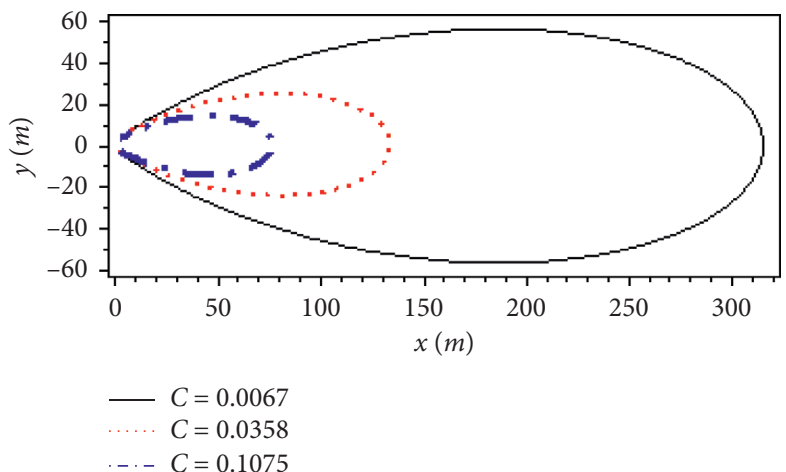

(a)

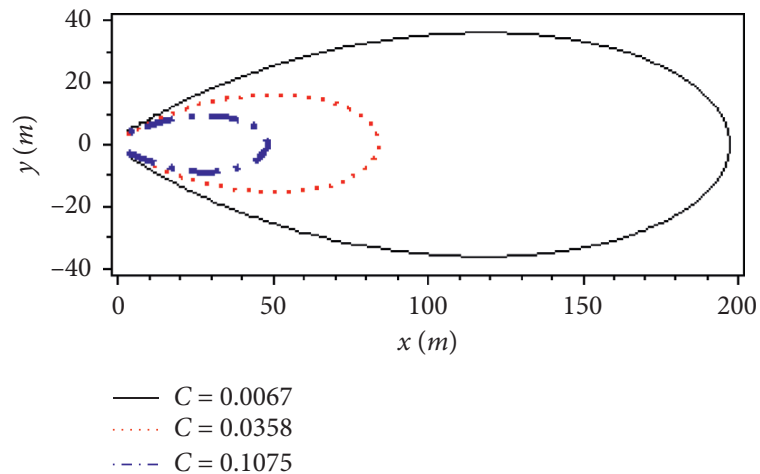

(b)

Figure 10: Continued. 


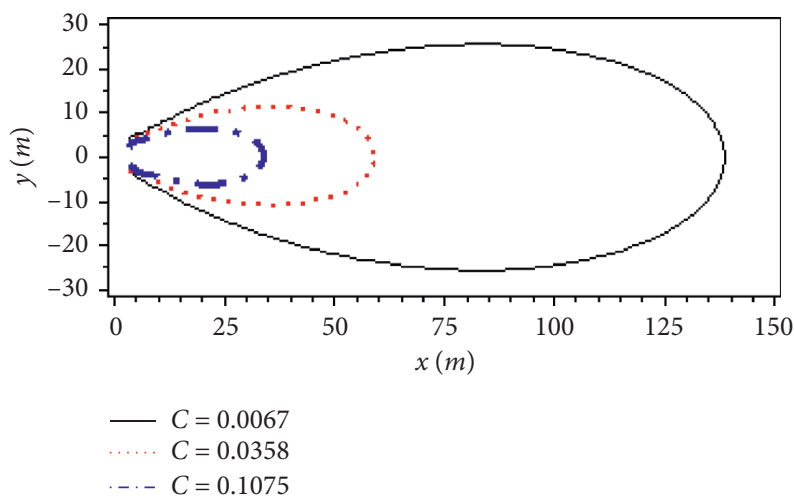

(c)

Figure 10: Concentration contours of continuous gas diffusion with different wind speeds $(Q=173 \mathrm{~kg} / \mathrm{s}$ and atmospheric stability class is C). (a) $u=2 \mathrm{~m} / \mathrm{s}$. (b) $u=5 \mathrm{~m} / \mathrm{s}$. (c) $u=10 \mathrm{~m} / \mathrm{s}$.

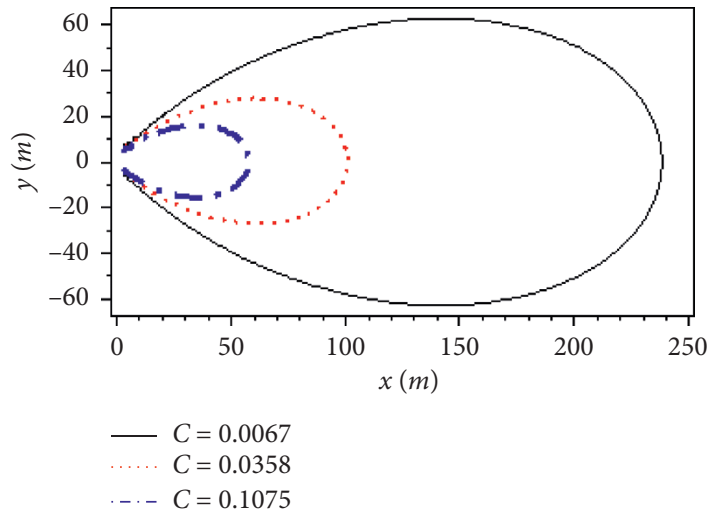

(a)

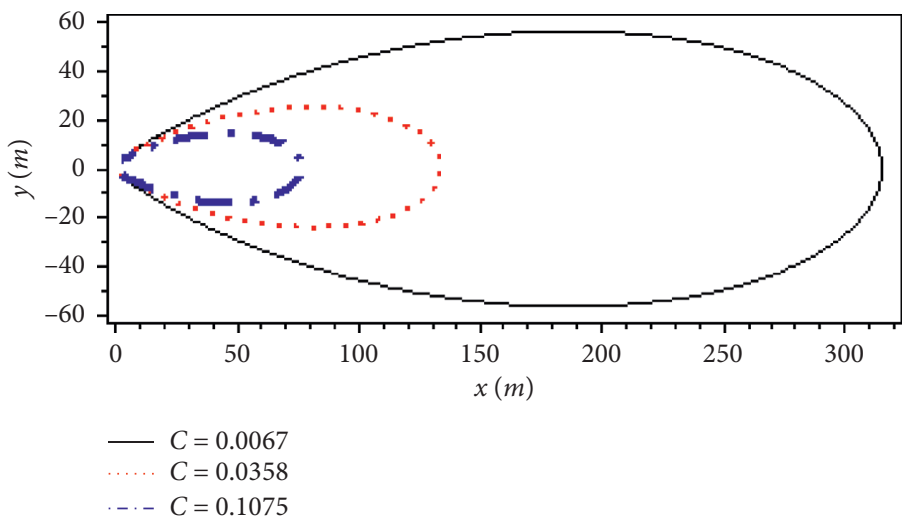

(b)

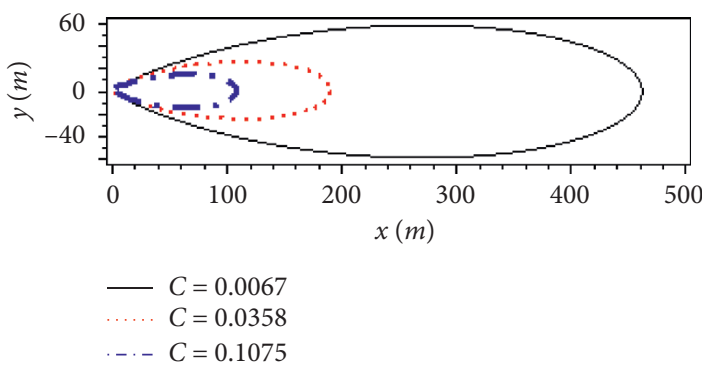

(c)

Figure 11: Concentration contours of continuous gas diffusion with different atmospheric classes $(Q=173 \mathrm{~kg} / \mathrm{s}$ and $u=2 \mathrm{~m} / \mathrm{s})$. (a) Atmospheric stability class is B. (b) Atmospheric stability class is C. (c) Atmospheric stability class is D.

occurs, after which point any leakage is monitored, with the gas diffusing freely to the surrounding spaces.

Herein, we assumed that the injection station was $80 \mathrm{~m}$ long and $60 \mathrm{~m}$ wide; moreover, the computational domain was $150 \times 100 \times 30 \mathrm{~m}$ and, to reduce the influence of boundary conditions on the simulations, the positive direction of the $x$-axis was east, the positive direction of the $y$ axis was north, and the $z$-axis was the vertical direction. Based on the real device layout of the injection station, the model was constructed using Gambit software; unstructured grids and size functions were used for meshing; grids were smaller for leak source and obstructions; after polyhedral mesh conversion, the final grid had a total of $3,324,044$. The injection-station model is shown in Figure 12.

In Fluent, the turbulence model was selected as the standard turbulence $k-\varepsilon$ model, the gas-release simulation was set as the subsonic velocity leak, the incompressible ideal-gas model was selected, and the pressure-based implicit solver was applied. Simulations consisted of three phases: basic wind-field building at different wind 


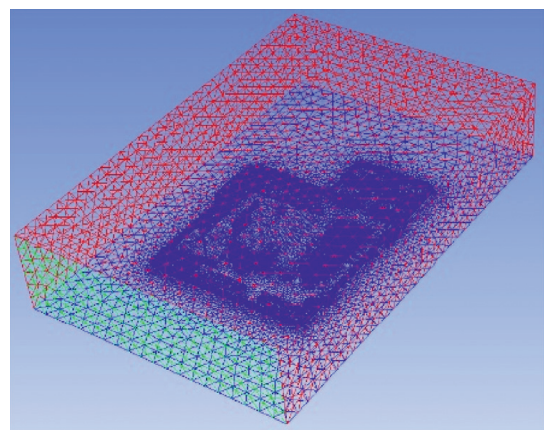

(a)



(b)

Figure 12: Numerical model of the injection station. (a) Surface grid of the calculate zone. (b) Enlarged partial grid.

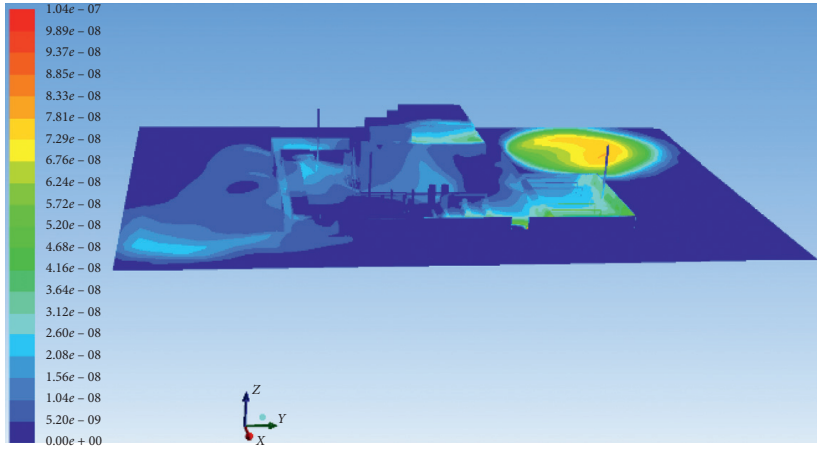

(a)

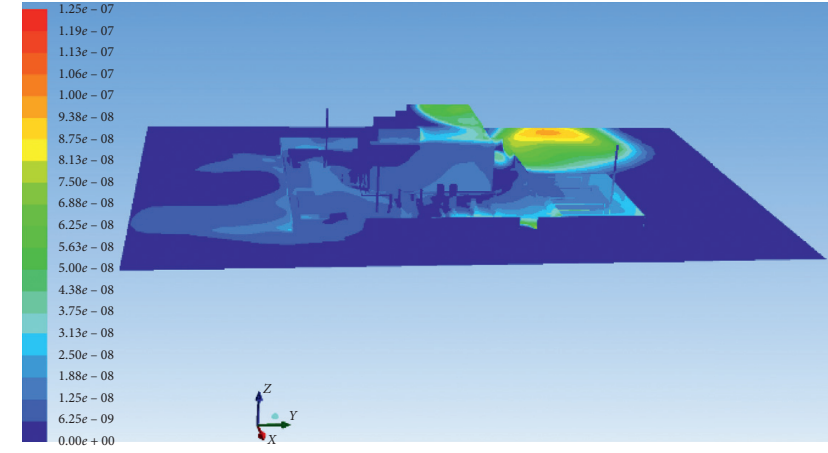

(b)

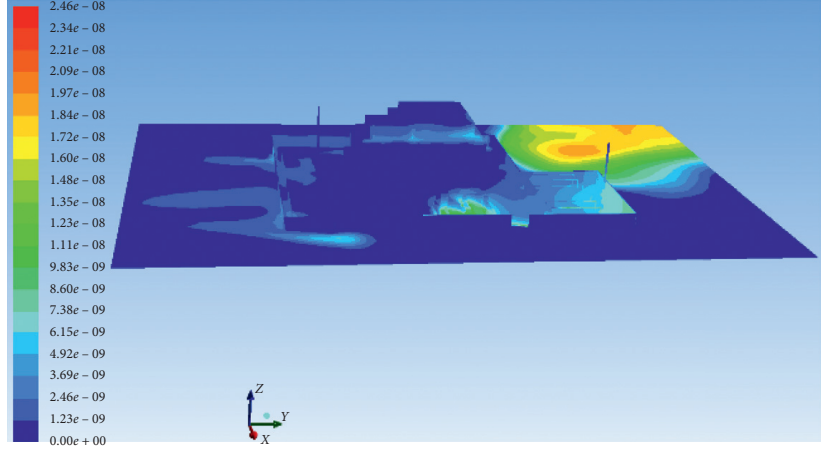

(c)

Figure 13: Simulation results of concentration-field ( $t=180 \mathrm{~s}$ ). (a) $u=2 \mathrm{~m} / \mathrm{s}$. (b) $u=5 \mathrm{~m} / \mathrm{s}$. (c) $u=10 \mathrm{~m} / \mathrm{s}$.

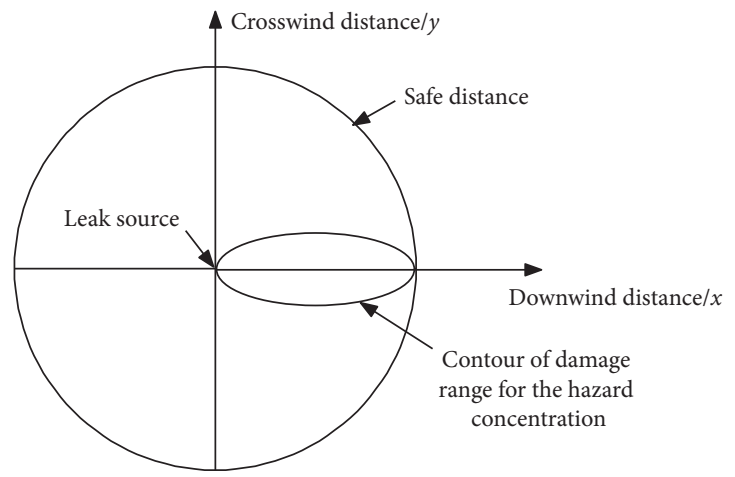

FIGURE 14: Schematic to determine the safety distance with the damage range of the hazard diffusion concentration. 


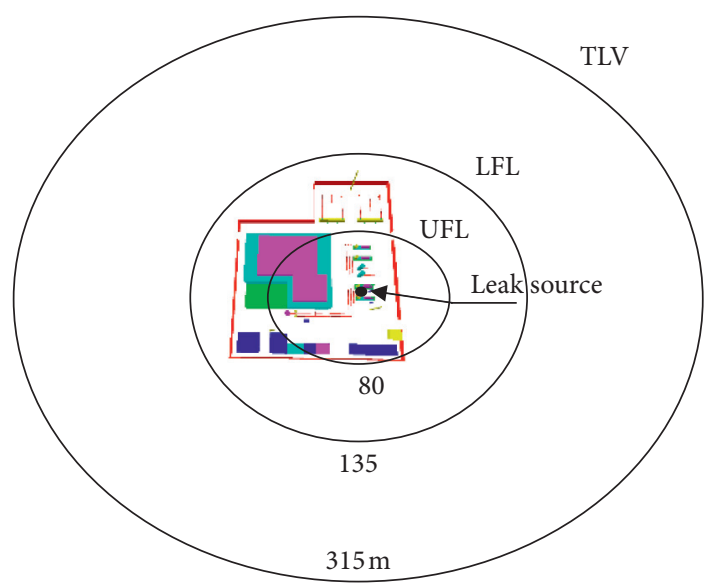

FIGURE 15: Hazardous zone of natural gas diffusion from a gas-storage cavern in salt rock.

directions; initial five minutes of continuous leakage on the basis of a basic wind field; three minutes of free diffusion in the atmosphere after leakage stopped. Simulation results are shown in Figure 13.

According to Figure 13, when the wind speed is increased, the gas cloud drifts further than it would otherwise; moreover, the area of personnel symptoms and the explosive concentration region are both greater when instantaneous leakage occurs.

The calculation concentration contour is elliptic under windy conditions, as can be seen in Figures 10 and 11. When determining the safety distance, all wind directions should be taken into account to identify the damage radius, the value of which is the safe distance for the downwind direction. Therefore, the elliptic-scope hazard range can be extended to take one a circular shape, the radius of which is the downwind direction distance, as shown in Figure 14.

According to the concentration-field distribution of the theoretical calculation in Section 4.1 and the Fluent simulations, the hazardous areas of gas diffusion from the sample gas-storage cavern in salt rock can be advised, as shown in Figure 15.

\section{Conclusions}

In this paper, an integrated analysis method was proposed to assess the hazard area of dispersion caused by accidental leakage from underground gas-storage caverns in salt rock. The Gaussian plume model was used to calculate the hazard area of dispersion caused by continuous leakage and Fluent was selected to simulate the hazard area of dispersion caused by instantaneous leakage. The proposed method was validated by comparing the calculation and numerical-simulation results with the experimental data. Furthermore, a sample underground gas-storage cavern in the salt rock was investigated; the TLV, UFL, and LFL distances resulting from natural gas dispersion were obtained using theoretical analysis and numerical simulation. Moreover, the factors that influence the hazard range of dispersion were discussed. The results indicated that the hazard area decreases with an increase in wind speed and a decrease in atmospheric stability when the leakage is continuous. However, the hazard area decreases with a decrease in wind speed when the leakage is instantaneous.

\section{Data Availability}

The data used to support the findings of this study are included within the article.

\section{Conflicts of Interest}

The authors declare that they have no conflicts of interest.

\section{Acknowledgments}

The authors gratefully acknowledge the financial support from the Natural Science Foundation of Jiangsu Province of China (Grant nos. BK20180081 and BK20190571) and the National Basic Research Program of China (973 Program) (Grant no. 2015CB058000).

\section{References}

[1] P. Bérest and B. Brouard, "Safety of salt caverns used for underground storage blow out; mechanical instability; seepage; cavern abandonment," Oil \& Gas Science and Technology, vol. 58, no. 3, pp. 361-384, 2003.

[2] L. F. Li, X. W. Zhao, J. H. Luo, H. Zhang, H. J. Yang, and X. Li, "Failure analysis of underground salt cavern gas storage and countermeasures," Oil \& Gas Storage and Transportation, vol. 29, no. 6, pp. 407-410, 2010.

[3] P. L. Wickenhauser, B. T. Wagg, and F. A. Barbuto, "Quantitative risk assessment-underground natural gas storage facilities," in Proceedings of IPC 2006: International Pipeline Conference, vol. 29, Calgary, Canada, September 2006.

[4] L. H. Xie, H. L. Li, X. W. Zhao, and H. Zhang, "Statistics and risk analysis of underground gas storage accidents in salt caverns," China Safety Science Journal, vol. 19, no. 9, pp. 125-131, 2009.

[5] C. H. Yang, W. G. Liang, D. H. Wei, and H. J. Yang, "Investigation on possibility of energy storage in salt rock in 
China," Chinese Journal of Rock Mechanics and Engineering, vol. 24, no. 24, pp. 4409-4417, 2005.

[6] J. Y. Zheng, X. K. Ma, and X. P. Yin, The Safety of Long Pipeline (Risk Identification, Evaluation and Control), Chemical Industry Press, Beijing, China, 2004.

[7] Z. Q. Wang, The Study of Leakage Model and Consequence Area of High-Pressure Gas Pipeline, China University of Geosciences, Beijing, China, 2009.

[8] S. Heusermann, O. Rolfs, and U. Schmidt, "Nonlinear finiteelement analysis of solution mined storage caverns in rock salt using the LUBBY2 constitutive model," Computers \& Structures, vol. 81, no. 8-11, pp. 629-638, 2003.

[9] H.-M. Kim, D. Park, D.-W. Ryu, and W.-K. Song, "Parametric sensitivity analysis of ground uplift above pressurized underground rock caverns," Engineering Geology, vol. 136, pp. 60-65, 2012.

[10] I. Contrucci, E. Klein, N.-T. Cao, X. Daupley, and P. Bigarré, "Multi-parameter monitoring of a solution mining cavern collapse: first insight of precursors," Comptes Rendus Geoscience, vol. 343, no. 1, pp. 1-10, 2011.

[11] W. Z. Chen, X. J. Tan, G. J. Wu, and J. P. Yang, "Research on gas seepage law in laminated salt rock gas storage," Chinese Journal of Rock Mechanics and Engineering, vol. 28, no. 7, pp. 1297-1304, 2009.

[12] T. T. Wang, X. Z. Yan, X. J. Yang, and H. L. Yang, "Dynamic subsidence prediction of ground surface above salt cavern gas storage considering the creep of rock salt," Scientia Sinica Techologica, vol. 41, no. 5, pp. 687-692, 2011.

[13] L. J. Ma, X. Y. Liu, H. F. Xu, S. G. Yang, and Z. J. Wang, "Stability analysis of salt rock gas storage cavern under uncontrolled blowout," Rock and Soil Mechanics, vol. 32, no. 9, pp. 2791-2797, 2011.

[14] S. G. Yang, Q. Fang, and Y. D. Zhang, "Consequence quantitative analysis of jet fire caused by gas leakage from underground gas storage caverns in salt rock," Chinese Journal of Rock Mechanics and Engineering, vol. 31, no. 9, pp. 1846-1853, 2012.

[15] Ministry of Housing and Urban-Rural Development and General Administration of Quality Supervision and Quarantine, GB50493-2009 Design Code for Detection and Alarm of Combustible and Toxic Gases in Petrochemical Industry, China Planning Press, Beijing, China, 2009.

[16] Petroleum and Natural Gas Industry Standard of China, SY6503-2008 Safety Technical Specification for Combustible Gas Detection and Alarm System in Petroleum and Natural Gas Engineering, Petroleum Industry Press, Beijing, China, 2008.

[17] CCPS, Guidelines for Use of Vapor Cloud Dispersion Models, Center for Chemical Process Safety of the American Institute of Chemical Engineers, New York, NY, USA, 2nd edition, 1996.

[18] D. M. Yu, Quantitative Risk Analysis of Flammable、Explosive and Poisonous Dander in Storage and Transport Process, China Railway Press, Beijing, China, 2000.

[19] T. Y. Long, Y. X. Su, W. Y. Xiang, and C. He, Computational Fluid Dynamics, Chongqing University Press, Chongqing, China, 2007.

[20] D. A. Crowl and J. F. Louvar, Chemical Process Safety: Fundamentals with Applications, Prentice-Hall, Upper Saddle River, NJ, USA, 2nd edition, 2002.

[21] CCPS, Guidelines for Consequence Analysis of Chemical Releases, Center for Chemical Process Safety of the American Institute of Chemical Engineers, New York, NY, USA, 1999.
[22] J. M. He, G. D. Ma, and S. X. Wang, Air Pollution Control Engineering, Higher Education Press, Beijing, China, 2010.

[23] N. Nevers, Air Pollution Control Engineering, McGraw-Hall Companies, Inc., 2nd edition, 2000.

[24] L. J. Wei, Numerical Simulation of Heavy Gas Dispersion, Beijing University of Chemical Technology, Beijing, China, 2000.

[25] X. H. Pan, Theoretical and Experimental Study on Dynamics Process for Accident of Release, Nanjing University of Technology, Nanjing, China, 2004.

[26] Z. Z. Han, J. Wang, and X. P. Lang, FLUENT: Example and Application of Fluid Engineering Simulation, Beijing Institute of Technology Press, Beijing, China, 2004.

[27] G. Q. Xu, The Study of Leakage and Dispersion of Flammable and Toxic Gas, Dalian University of Technology, Dalian, China, 1998.

[28] L. H. Anay, P. K. Ronald, and L. E. Donald, "On the application of computational fluid dynamics codes for liquefied natural gas dispersion," Journal of Hazardous Materials, vol. 140, pp. 504-517, 2007.

[29] S. Spyros and R. Fotis, "Simulation of Coyote series trials-part I: CFD estimation of non-isothermal LNG releases and comparison with box-model predictions," Chemical Engineering Science, vol. 61, pp. 1434-1443, 2006.

[30] S. G. Yang, Q. Fang, Y. D. Zhang, and L. J. Ma, “Analytical method for gas leakage mass from underground gas storage caverns in salt rock," Chinese Journal of Rock Mechanics and Engineering, vol. 31, no. S2, pp. 3710-3715, 2012.

[31] B. Zhang, G. M. Chen, J. H. Gong, and Y. Wang, "Optimization of gas detection and alarm instrument networks at gas gathering station based on CFD," Journal of China University of Petroleum (Edition of Natural Science), vol. 34, no. 5, pp. 141-146, 2010. 